\title{
CAUSES FOR INEFFECTIVE COMMUNICATION BETWEEN MEDICAL SPECIALISTS
}

\author{
Stayko I. Spiridonov, \\ Department of Health Policy and Management, Faculty of Public Health, \\ Medical University - Sofia, Bulgaria.
}

\section{SUMMARY}

Purpose: In the resent years the healthcare system has moved to inter-professional, cross-disciplinary, multiperson approach where the communications are very important for ensuring patient safety. Communication in health organisations needs to be studied and analysed deeply and comprehensively because the future of an organisation often depends on good communication. The purpose of this study is to investigate and analyse the reasons for ineffective communication between medical specialists in the teams they work in.

Materials and Methods: A questionnaire method is used. Through a survey over a period of 12 months (from 01. 12. 2014 to 01. 12. 2015) at the Escullap Hospital in Pazardzhik, DCC 18 - Sofia, St. Mina Hospital in Plovdiv, MHAT - Plovdiv, DCC 1 in Haskovo, UMHAT in Stara Zagora, DCC 3 in Varna and MHAT - Parvomay, was studied and analyzed the opinion of medical specialists on the effectiveness of communication within the team they work in. The survey includes 477 medical specialists.

Results and conclusions: According to $41.1 \%$ of the respondents, the communication in the team they work in is insufficiently effective. Most of the respondents $(39.8 \%)$ find their colleagues responsible for the ineffective communication, followed by those who seek the cause for poor communication in the management of the health care facility $(27.6 \%)$. The leading cause of poor communication in the team according to the study participants is the inequality between the characters of the colleagues $(41.9 \%)$. According to the majority of respondents $(28.3 \%)$, improvements in facilities and wage increases (27.3\%) would be essential to improve communication within the team they work in. Recommendations have been formulated to improve communication among medical specialists.

Keywords: communication, medical specialists, efficiency,

\section{INTRODUCTION}

Communication in health organisations needs to be studied and analysed deeply and comprehensively. The future of an organisation often depends on good communication. It is necessary to study the many aspects of business communication: its objectives, strategies, the obsta- cles in communication, the ways to communicate more effectively, the basic principles of business contacts, the types of communication and, last but not least, the forms of business communication (verbal, nonverbal , Epistolary, public speaking and telephone communication) $[1,2]$. Zillich mentioned that recognition of these drivers might help medical specialist developing collaborative working relationships [3]. The knowledge of all these aspects of the communication process in the business environment enables anyone who wants to be a professional to review their behaviour and way of expression during communication and to achieve the necessary communication skills.

In the resent years the healthcare system has moved to inter-professional, cross-disciplinary, multi-person approach where the communications are very important for ensuring patient safety. The communication inefficiency is a prerequisite for worsening teamwork and extent the possibilities of error in the health services delivering [4]. With the health and safety of patients at stake, learning to communicate effectively and efficiently with all members of the patient-care team is critical [5].

The purpose of this study is to investigate and analyse the reasons for ineffective communication between medical specialists in the teams they work in.

To achieve this goal, we set out the following main tasks:

1. To explore the opinion of medical specialists on the effectiveness of communication within the team they work in.

2. To identify the most common causes for inefficient communication within the team according to respondents.

3 . To clarify the specific causes for poor communication within a team.

4. To investigate the preferred measures to improve team communication according to survey participants.

5. To formulate recommendations for improving communication between medical specialists.

\section{MATERIAL AND METHODS}

A questionnaire method is used to objectify the observed results. The survey was conducted over a period of 12 months (from 01.12.2014 to 01.12.2015) at the Escullap Hospital in Pazardzhik, DCC 18 - Sofia, St. Mina Hospital in Plovdiv, MHAT - Plovdiv, DCC 1 in Haskovo, UMHAT in Stara Zagora, DCC 3 in Varna and MHAT - 
Parvomay.

The survey includes 477 medical specialists, inc. doctors, nurses, midwives and paramedics working at the health facilities covered.

Quantitative analyses were made with a statistical suite of application programs - SPSS 17.0. For table and graphic processing and presentation were used the MICROSOFT OFFICE products.

\section{RESULTS AND DISCUSSION}

Out of the survey participants, the largest share is in the age range between forty-fifty years - a total of thirtyseven people or $28.7 \%$ of all respondents. The smallest group in our study is the group of health workers over the age of sixty $-11.7 \%$. (Figure 1 ).

Fig. 1. Age structure of respondents

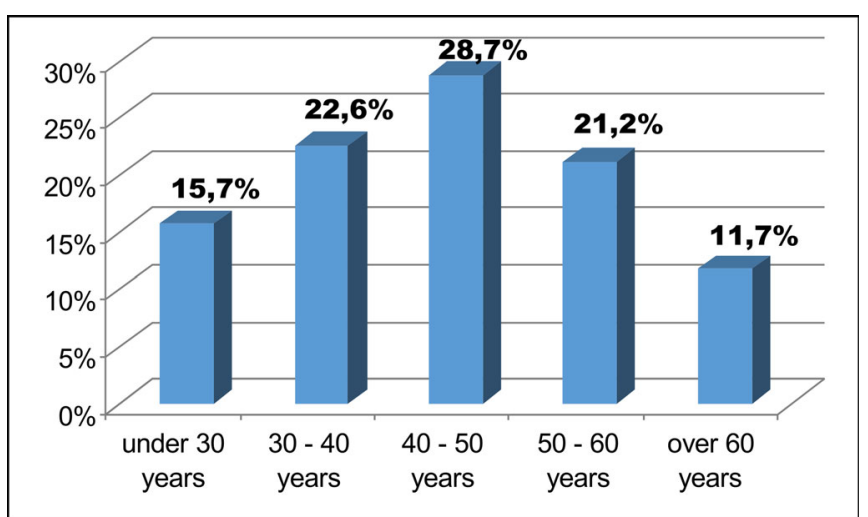

The frequency of the respondents' distribution in our survey according to their job description shows that the largest share is that of nurses and midwives - $46.5 \%$ and the share of doctors is almost as much $-45,1 \%$. The survey also includes managers $(5.9 \%)$ and parsers $(2.5 \%)$, but with relatively less representation.

We surveyed the respondents' opinion on the effectiveness of communication in the team they work in. According to $54.1 \%$, communication is sufficiently effective (Figure 2).

Fig. 2. Frequency of the respondents' distribution on the effectiveness of communication in the team they work in

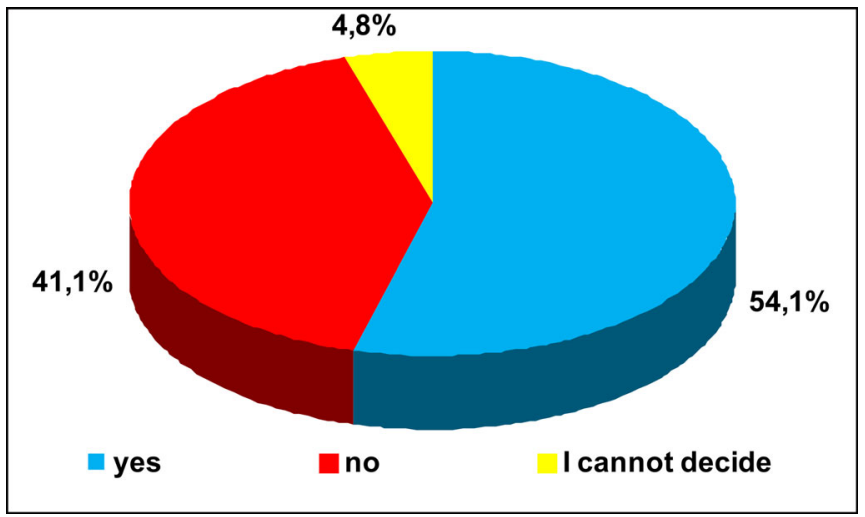

The active and effective communication between all members is very important for providing efficient health services [5]. Stephen and McPhee sited that communication between the medical specialists may be improved by suppling more clinical information and direct contact [6].

In order to find out the reasons for the ineffective communication in the team according to the survey participants, we asked the next question in the survey. (Figure 3)

Fig. 3. Most common reasons for inefficient communication in the team according to respondents

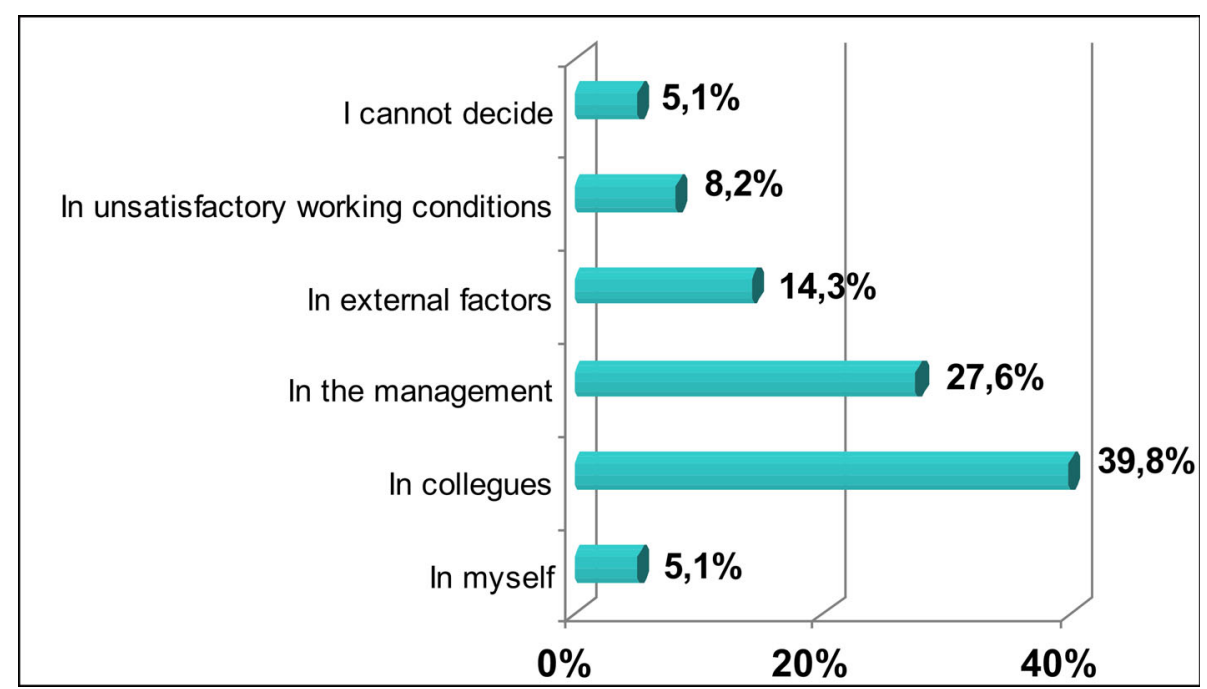


Most of the respondents (39.8\%) find their collegues responsible for the ineffective communication. The second largest is the group of those who seek the cause for poor communication in the management of the health care facility $(27,6 \%)$ they work in.

We also tried to investigate the specific causes for poor communication in a team. There is a predominant view that the leading cause of poor communication in the team is the inequality between the characters of the colleagues. This is the opinion of $41,9 \%$ of the respondents. The second most important cause, according to medical specialists, is the poor pay, which in their opinion creates a prerequisite for strained relations in the team (Figure 4).

Fig. 4. Most common causes for poor communication in the team of respondents

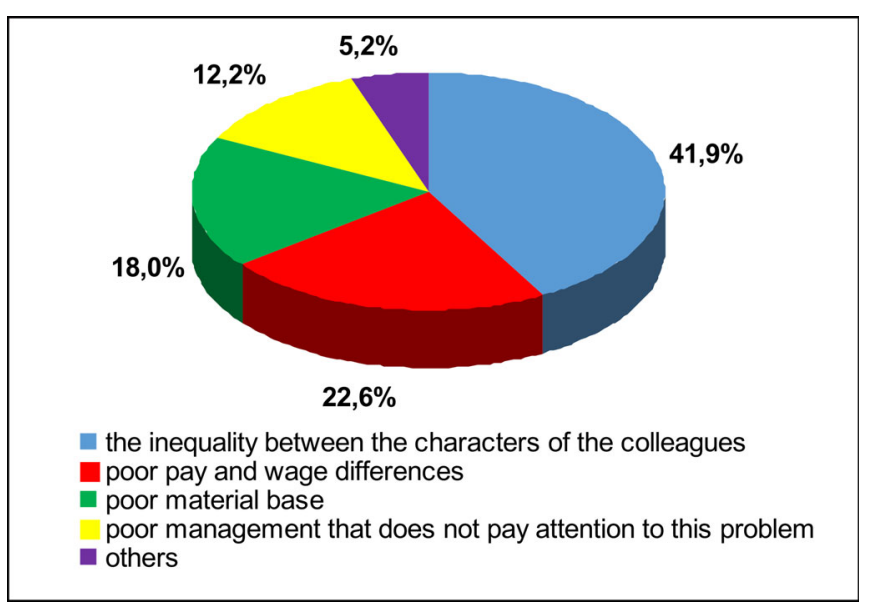

Investigating the opinion of the participants in the survey, we found that, according to the majority of them (28.3\%), the improvement of the facilities will be essential for improving the communication within the team they work in. The second $(27,3 \%)$ are those medical specialists who believe that wage increase would also lead to better communication with their colleagues. A lot of the respondents $(18.0 \%)$ attach importance to the role of team building activities to communication improving (Figure 5).

Fig. 5. Preferred measures for improving team communication according to survey participants.

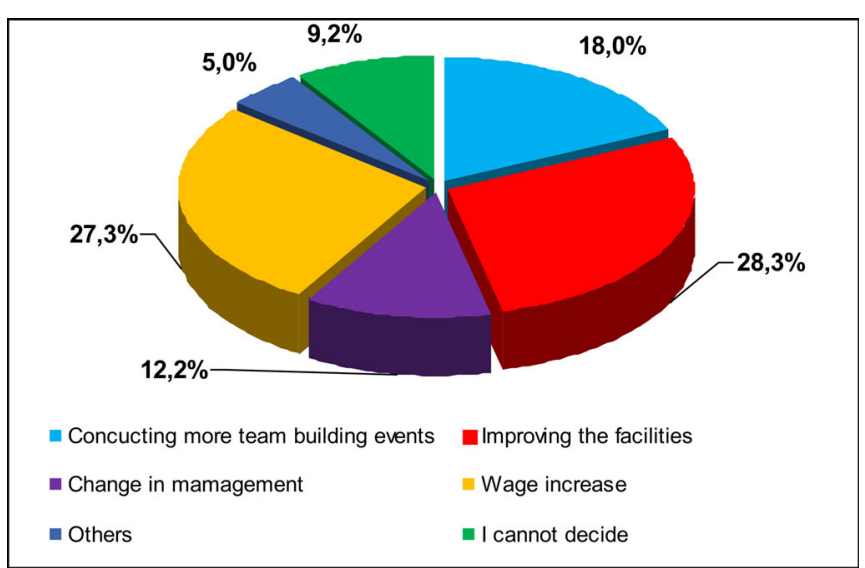

\section{CONCLUSIONS}

Based on the analysis of respondents' opinion on the causes for ineffective communication between medical specialists in the teams they work in, the following conclusions can be drawn:

1. According to $41.1 \%$ of the respondents, the communication in the team they work in is insufficiently effective.

2. Most respondents $(39,8 \%)$ find their collegues responsible for the ineffective communication, followed by those who seek the cause for poor communication in the management of the health care facility $(27,6 \%)$.

3 . The main cause for poor communication in the team according to the participants in the study is the inequality between the characters of the colleagues $(41.9 \%)$.

4. According to the majority of respondents (28.3\%), improvements in equipment and wage increases (27.3\%) will be essential to improving communication within the team they work in.

The analysis of the conclusions and summaries made on the basis of the research conducted and the need to solve the problems examined allow us to make recommendations to the health managers who would like to use ably communication as a management tool and as a method of improving the relationships within the team:

1. In-depth study of the motivation of health workers with the purpose of improving the level and effectiveness of communication in work relationships.

2. Provision of periodic training on the impact of communication skills on improving the relationships between professionals working in a medical team.

3. Development of a test program to clarify the risk of deterioration of the relationships within the team, which will determine individually the opportunities for improvement of the participants' communicative abilities, leading to a number of favourable consequences. 


\section{REFERENCES:}

1. Vodenicharov T. Professional health management has no alternative. Medical Meridians. 2014; 2:3-7. [in Bulgarian]

2. Dimitrov I. Influence of communicative skills on the basic characteristics of the working environment in health organizations, PhD Thesis, 2016, pp. 61-64. [in Bulgarian]

3. Zillich AJ, McDonough RP,
Carter BL, Doucette WR. Influential characteristics of physician/pharmacist collaborative relationships. Ann Pharmacother. 2004 May;38(5):76470. [PubMed] [CrossRef]

4. Palanisamy R, Verville J. Factors Enabling Communication-Based Collaboration in Interprofessional Healthcare Practice: A Case Study. Int J e-Collaboration (IJeC). 2015
April; 11(2):8-27. [CrossRef]

5. Woods JA, Jackson DJ, Alston GL. Interprofessional communication. Drug Topics. 2011 Aug;155(8):42-51.

6. McPhee SJ, Lo B, Saika GY, Meltzer R. How good is communication between primary care physicians and subspecialty consultants? Arch Intern Med. 1984 Jun;144(6):1265-8. [PubMed] [CrossRef]

Please cite this article as: Spiridonov SI. Causes for Ineffective Communication between Medical Specialists. J of IMAB. 2017 Jul-Sep;23(3):1623-1626. DOI: https://doi.org/10.5272/jimab.2017233.1623

Received: 06/05/2017; Published online: 03/07/2017

\section{Address for correspondence:}

Assoc. Prof. Stayko Ivanov Spiridonov, MD

Department of Health Policy and Management, Faculty of Public Health, Medical University - Sofia.

8, Bialo more str., fl. 5; 1527 Sofia, Bulgaria.

Tel.: +359898642646

E-mail: sspiridonov@abv.bg 